\title{
Yalan ve Tiyatro
}

\author{
Müşerref ÖZTÜRK ÇETINDOC̆AN *
}

O̊zet

İnsanoğlu sözlü iletişime geçtiği zamanlardan bu yana yalan söyler. Kişinin kendini korumak uğruna, niyetini bir başkasından gizleyerek söylediği yalanlar, gerçekleri akla uydurmanın yolu kabul edilir. Gerçeklik ve yaşananlar arasında tam bir uyum olmadığında yalan ortaya çıkar. Felsefede yalan, doğrudan tartışılmayıp hakikatin görünür hale gelmesini sağlayan diyalektik bir ilişkiyle ele alınır. Yaratıcı bir işleve sahip olan yalan, bir dil oyunu olarak görülür ve hakikat ancak yalan'la görünür hale gelir. Burada öncelikle, felsefeden yola çıkarak yalanın hakikatle olan bağı tartışılmakta ve bu bağlamda tiyatro sanatının kurmacaya dayalı doğası yeniden ele alınmaktadır. Çünkü tiyatro sanatı mimesisin doğası gereği bir kurgulama eylemidir -ki bu eylemin özü, seyirciyi bir yalana inandırmaya dayanır. Gerçeğin '-mış gibi’ yapılarak taklit edilmesiyle başlayan sahneleme, seyircinin kandırılması değil, aksine bilinçli bir şekilde seyircinin yalana ortak oluşuyla paylaşılan bir estetiktir. Dolayısıyla bu çalışmanın asıl amacı, gerçekliğin içinde yalandan olanı tercih eden 'seyreden insan'ın - 'homo videns'in gerekçelerini sorgulamaktır.

Anahtar Sözcükler: Yalan, Hakikat, Felsefe, Tiyatro, Mimesis.

\section{Lie and Theatre}

\section{Abstract}

Human beings have been telling lies since the time they achieved verbal communication. Lies which are told to protect one's self by hiding his/her intentions from others are accepted as a way of adapting the facts to mind. They reveal when there is no complete harmony between the reality and happened. In philosophy, lie is dealt with dialectical relationship which helps the truth be appeared instead of being discussed directly. The lie that has a creative function is a language game and the truth can become visible by lie. First, based on the philosophy, the relationship between lie and truth is being discussed and the nature of theatre based on fiction is being talked. Because theatre is on editing action because of the nature of mimes and the essence of this action is based on a lie to convince the audience. Beginning with the act of mimicking the reality with "as if" the act of staging is an aesthetic shared not by lying to the audience but by their conscious preference of believing that lie. Therefore, the main purpose of this study is to question the reasons for the 'spectator' - 'homo videns' who prefer to lie in the reality.

Keywords: Lie, Truth, Philosophy, Theatre, Mimesis. 


\section{Giriş}

“Sanat, gerçekleri tanımamıza yardımcı olan bir yalandır." Pablo Picasso (Mayer, 2008: 37)

Yalan, ikinci bir kişinin varlığı söz konusu olduğunda söylenmeye başlanan, insanlık tarihinde 'gülme' gibi köklü bir geçmişe sahip olan insani bir gerçekliktir. Adem ile Havva'nın bir elma yüzünden birbirine düştüğü, şeytanın cennetten yalan yüzünden kovulduğu, yılanın iyi bir melekken yine bir yalan uğruna sürüngene dönüştürüldüğü mitlerden bu yana yalan söylenir ve söylendiğinde kıyametin kopmadığı anlaşılınca yalan, günlük yaşamın gerçekliği içinde vazgeçilmez bir 'hakikate' dönüşür. Tanrılar arasında geçen olayların anlatıldığı pagan kültürlerin kırsal mitlerinde - özellikle Antik Yunan mitolojisinde yalancılığıyla övgü alan hırsız tanrı Hermes'ten, tanrıların tanrısı çapkın Zeus'a kadar olumlanan yalan, tanrısal bir maharet gibi anlatılır. 'Bozacının şahidi şıracı' deyiminin taşıyıcısı gibidir bu iki tanrı, çünkü Hermes, Zeus'un özel ulağı, kapı bekçisi ve Maia'dan doğan oğludur. Baba-oğlun neredeyse tek iletişim aracı, ortak yalanları ya da birbirlerinin yalanlarını görünmez hale getirmek için kurdukları eğlenceli dolantılardır (Bayladı, 2007: 82-86). Yine de tanrıların eğlencesi haline gelen yalan-dolan oyunları, özellikle Zeus'un gönlünü eğlendirmek adına yaptıkları, Roma tiyatrosunda Plautus'un (1974), 17. yüzyıl Fransız tiyatrosunda Moliere'in (1965) 'Amphitryon' adlı komedyalarına konu olur.

Her iki oyunun olay dizisi mitolojideki hikayesiyle oluşturulur: Zeus, efsane komutan Amphitryon'un hamile karısı Alkmene'ye göz koyar ve onunla birlikte olabilmek için Amphitryon'un görünümüne bürünür. Kocasıyla birlikte olduğunu sanan zavallı kadın hiçbir şeyden şüphelenmez. Gece Tanrısı, Zeus'un emriyle arabasını çekip gitmez, Güneş Tanrı doğmak bilmez, Hermes ise kapıda beklemektedir. Savaştan zaferle dönen Amphitryon Sosios'u-Roma'da köle, 17. yüzyılda hizmetçi olarak kullanılan- önceden eve gönderir fakat Hermes de
Sosios kılığındadır. Bu karşılaşmanın yarattığı durumun komiği seyirciyi kahkahayla güldürürken Amphitryon, insanlık tarihinin aldatılan ilk erkeği olarak tarihe geçer. Zeus'un bu birlikteliğinden mitolojinin 'trajik kahramanı' olarak bilinen ünlü ismi Herakles dünyaya gelecektir ve Zeus'a göre Amphitryon, böyle bir oğla sahip olduğu için ölümsüzleşecek olmasıyla avunmalı, Alkmene de, yalana, hileye, aldatılmış olmaya aldırmamalı; sonuçta ortaya çıkacak olan gerçekle övünmelidirler. Diğer bir deyişle yalan, önce tanrıların, iktidarın, yönetenin kullandığı bir araç haline gelir ve insanın yalan söyleme yetisi doğuştan gelen bir özellik olmayıp sonradan öğrenilir.

\section{Yalanın Tanımı ve Felsefede Ele Alınışı}

Yalan, "aldatılmak amacıyla bilerek ve gerçeğe aykırı olarak söylenen söz, (...) gerçek olmayan, asılsız, uydurma" (TDK, 1998: 2372) tanımıyla açıklanır. Herkesin mutlaka yalan söylediği düşüncesinden hareket ederek yalanın doğasını tanımaya çalışan, insanların neden yalan söylediğini ve ilişkilerde yalanın nasıl yakalanacağını araştıran Dr. Paul Seager ve Dr. Sandi Mann'ın (2010: 11) ifadesine göre ise yalan, "başarılı olsun ya da olmasın, söyleyenin aslında doğru olmadığını bildiği ve söylenen kişiye gerçek olmadığının bildirilmediği bir inanç yaratmak için sarf edilen kasti çabadır". İnsanın ikinci doğası olarak kabul edilen yalan, kasıtsız söylenmesi imkânsız olandır ve Claudia Mayer (2008: 12-25) yalanı, sosyalleşmenin getirdiği bir yeti olarak vazgeçilmez bulurken, aynı zamanda toplumsal bir uzlaştırıcı rolü üstlendiğini iddia ederek yalanın övülesi yanları olduğunu savunur. 'Beyaz yalan'lar olmazsa insanların bir arada bulunması zorlaşır, hayat çekilmez hale gelir fakat iyi niyetli söylenen küçük yalanlar, rengi beyaz bile olsa yalandır. Kişi iyi olmadığı halde 'nasılsın' sorusuna 'iyiyim' diye cevap verir -ki bu en sık karşılaşılan zararsız yalandır. Mayer'e göre bu tür yalanlar, birlikte yaşamanın zorunlu koşuludur.

Felsefede yalan, başlı başına bir sorunsal olarak ele alınmaz. 'Hakikat'in ne olduğunu bulabilmek için öncelikle hakikatolmayandanhareketedilirveböyleceyalanaulaşılır. 
Antik Yunan felsefecilerine göre yalan, olumsuzlanan bir durum değildir. Öyle ki, Homeros'un destanlarında yalanlarıla devleri oyuna getiren, Akhilleus'un savaşa gitmesi için hileler bulan Odysseus, kurnaz oluşuyla ve sıra dışı aklıyla hayranlık duyulan kahraman olur. Yalancılık, akıllı olmayı gerektirir ve söylenen yalana çevresindekileri inandırmak her yiğidin harcı değildir. Mitlerde de tanrıları, insanları aldatan tanrılar yalancılıkla eleştirilmeyip yine kurnazlıklarıyla yüceltilirler. Oysa insanın insana ve özellikle insanın tanrılara yalan söylemesi hoş karşılanmaz, mutlaka cezalandırılır. Tanrılara yalan söyleyenler Zeus'un gazabına uğrayarak Hades'in en karanlık katı olarak anlatılan Tartaros'a gönderilir - ki Tartaros, asla affedilmeyeceklerin ya da bir daha gün yüzü göremeyeceklerin diyarıdır. Sisyphos Zeus'u iki kez kandırmış, yalanlarıyla Hades'ten bile kaçmayı başarmış fakat sonunda bir kayayı dağın tepesine çıkarmakla cezalandırılarak Tartaros'a gönderilmiştir. Efsaneye göre, kaya tam zirveye geldiğinde yeniden aşağıya yuvarlanır ve Sisyphos bu mahkûmiyetiyle, ölümün bilinmezliği karşısında yaşamın absürdlüğünün dile getirilişi olarak simgeleştirilir.

Antik Yunan'da Platon, görünen her şeyin taklit yani yalan olduğunu savunmuş ve ünlü idealar teorisinde hakikatin ancak idealar dünyasında yer aldığına inanmıştır. Bu dünyadaki her şey bir kopyadır ve değersizdir. Platon'un karşısında yer alan Aristoteles ise hakikatin doğada aranması gerektiğini öne sürer. İki düşünürün hakikat üzerine görüşleri sanata ve tiyatroya bakışlarını da belirler. Platon tiyatroyu 'taklidin taklidi', 'kopyanın kopyası' olarak görüp olumsuzlarken Aristoteles, 'gerçeğin taklidi' nitelendirmesiyle sanatı ve tiyatroyu yeni bir üretim eylemi biçiminde ifade eder (Turgut, 1991: 16-33). Her iki düşünür de 'yalan'ı dolaylı olarak 'hakikat'in doğasıyla irdelemeye çalışır fakat antik dönemin erdem anlayışı, 'ölçülü olmak', 'ölçülü davranmak' üzerine kuruludur. Mitlerde yalan gerekçelendirilebilen, kurnazlığın ve aklın buyruğunda hizmet eden, kötücül olmayan bir yetidir. Platon'un bakışıyla hakikatin kendisinin 'yalan' olduğu bir dünyada, 'yalan'ı tartışmak ya da olumsuzlamak gereksizdir. Antik Yunan felsefesinin yeniden ele alındığı neoklasik dönemde Descartes, şüphe edilmeyecek biçimde açık ve seçik kanıt elde etmediği sürece, inandığı şeyin gerçekten doğru olduğundan emin değildir. Oysa Antik Yunan'da böyle bir şüphe yoktur. Hakikatin elde edilmesi, bir takım ahlaki niteliklere sahip olunmasıyla garanti altına alınır. Ahlaki niteliklere sahip olan, hakikate erişme imkânına da sahiptir (Foucault, 2005: 9-17). Yalanın günah, yalancının günahkâr sayılması ise, tek tanrılı dinlere geçildiğinde gündeme gelir.

Hıristiyanlık yayılmadan önce Tevrat'ta yalanı yasaklayan açık bir ifadeye rastlanmaz fakat gelecek nesillere yanlış izler bırakılmaması gerektiğinden söz edilir. On Emir arasında 'yalan söylemeyeceksin' maddesi yer almasa da, 'komşuna karşı yalan şahitlik yapmayacaksın' denilerek sadece adalet önünde dürüst davranmak gerektiğine vurgu yapılır. Hıristiyan ahlak anlayışındaysa hem yalan hem de yalancılık, affedilmez günahlar arasında kabul edilir. İsa'nın öğretisine göre, insanın 'evet'i 'evet', 'hayır'ı 'hayır' olmalıdır. Aslında sadece Hıristiyanlık değil, tüm dinler yalanı günahlar arasında sayar ve bir ahlaksızlık olarak değerlendirir. Kur'an-ı Kerim'de üç yüzdenfazla ayette yalanın kötülükleri anlatılır. Yalan en büyük günahlardan biri, yalancılık ise huyların en kötüsü olarak görülür (Oral, 2004: 121138). Aksine doğruluk, 'iyi insan' olmanın vazgeçilmez koşuludur. Yine de yalan Ortaçağ’a gelinceye kadar kötücül bir günah olarak görülmemiştir. Dönemin ünlü filozofu Augustinus, - ilk kez - yalanı insanlığın kalıtımsal günahı kabul ederek lanetler ve ona göre yalan, insan ruhuna azap çektiren temel kötülüklerden biridir (Mayer, 2008: 2427). Batı felsefesi, Hıristiyanlık ahlak görüşünün etkisiyle ‘yalan’a yeni bakış açıları getirse de amaç daima, hakikatin yüceltilmesidir - çünkü yalancı, en azından hakikatin ne olduğunu bildiği farz edilen kişidir ve insana 'yalancı' sıfatını ekleyen de hakikatin bilgisidir ya da "yalancının yalanı, kendi kişisel hakikatidir” (Forrester, 1999: 17). Augustinus'un lanetli bir günah olarak nitelendirdiği yalan, hakikatin anlaşıımasını engellemekte, Tanrı vergisi olan 'doğru'yu bulanıklaştırmaktadır. Bu görüşe benzer 
bir yaklaşım sergileyen Kant da yalan söylemenin, kişinin kendi insanlığını reddetmesi, hakikati öğrenme hakkından feragat etmesi anlamına geldiğini iddia eder. Söylenen yalan, karşıdaki kişiye doğrudan zarar vermese de insanlığın ahlaksal bütünlüğünü tahribata uğratmaktadır (Forrester, 1999: 31-34).

Rönesans'la birlikte hızla değişen ve zenginleşen burjuva sınıfı, monarşinin dine dayalı ahlak anlayışını sarsınca yerine paraya dayalı yeni bakış açıları getirilir. Ticarette başarıya götüren her yol mubahtır ve yalan, zarar vermediği sürece kötü değildir. Hatta söylenen yalan, Voltaire'e göre iyilik getiriyorsa erdem olarak kabul edilmelidir (Williams, 2006: 22-25). Kapitalizmin görünür hale geldiği yükselen burjuva ahlak anlayışı, günümüze kadar evrilen bir yapı içermesiyle yalanın varlığını yadsımaz, bilakis, herkesin yalan söylediği bir dünyada yalan söylememenin aptallık olduğu bilinci yaratılır. Çünkü paraya dayalı ilişkilerde sosyal bağlar nesneleşir ve ahlakı belirleyen parasal hakikatlerin ve yalanların oluşmasına neden olur. Tüccarın malını satabilmek için yalan söylemesi ticaretin cilvesi olarak görülen bir hakikate dönüşür. Kapitalizmin görünür hale geldiği yeni toplum düzenlerine rağmen felsefe hakikat'in ne olduğunu aramayı sürdürür.

Hakikatin varlığını yalanla diyalektik bir ilişki içinde gören düşünürlerden olan Francis Bacon, insan doğasında bulunan egemen 'iyi'nin kavranabilmesi için hakikat bilgisi dışında 'hakikat inancı'nın da olması gerektiğine inanır. Çünkü hakiki olan, varlığın kendisine uygun düşen; yalan olan ya da hakiki olmayan ise varlığın algılanmasını engelleyendir. Benzer bir görüşe sahip olan Sartre, bilincin ancak yalan yoluyla Öteki'nden gizlenmiş halde var olabileceğini ileri sürer (Tepe, 2003: 75-84). Hakikat yalanın karşısında cesurca durmasa varlığının anlaşılması imkânsız hale gelir ve Wittgenstein'a göre, yalan bir dil oyunudur. 'Mitomani', yani yalan söyleme hastalı̆̆ı, ancak sözcükler aracılığıyla ortaya çıkar ve yalan, yaratıcı bir işleve sahiptir. İnsanın sözcükler aracılığıyla iletişim kurmaya başlaması, hatalarına özür bulmak için mitleri kurgulamasıyla ilişkilidir. Alexander Koyre (1945), 'Yalan Üzerine Düşünceler' adlı makalesinde, “insanın sözle tanımlandığı bellidir ve söz yalan ihtimalini de beraberinde getirir ve yalan, gülmeden çok daha fazla insana özgü olan bir şeydir" (Forrester, 1999: 34) diyerek yalanın 'dil'de açığa çıktığını savunanlardan olur.

Nietzsche, hakikat-yalan diyalektiği üzerine en çok kafa yoranlardandır. 'Ahlak Ötesi Anlamda Hakikat ve Yalanlar Üzerine' adlı makalesinde dil, bir hakikat oyunu olarak ele alınır. Çünkü Nietzsche'ye göre hakikatin kendisi yalandır:

"Hakikatler yanılsama olduklarını unuttuğumuz yanılsamalardır; hakikatler alışkanlık haline gelmiş ve duyuş gücünü tüketmiş metaforlar, silinmiş ve artık para olarak değil, metal olarak alınan sikkelerdir... biz bu zamana kadar yalnızca toplumun var olmak için bize dayattığı görevin sesini dinledik: Doğruyu söylemek bu bildik metaforları kullanmak demektir. Demek ki, ahlaki bakımdan söyleyecek olursak, bu görev tespit edilmiş bir töreye göre yalan söyleme, sürüyle yalan söyleme ve bunu herkes için bağlayıcı olacak tarzda söyleme görevidir. Elbette, insanlar şeylerin söz gelimi böyle olduğunu unutur ve böylece bilmeden gerektiği şekilde ve çağlar boyu süren geleneğe uygun olarak yalan söyler -ve özellikle bu bilinçsizlik ve bu unutma yüzünden, insan bir hakikat duygusuna erişir." (Forrester, 1999: 49'dan).

Hakikat bir yalansa ve bu doğalsa, yalana yönelik olumsuz eleştiriler de yersizdir. Nietzsche'nin görüşlerinden yola çıkan Foucault da, gündelik hayatı 'hakikat oyunları' olarak adlandırır. Iktidarın varlığı, sosyal süreçler ve kuramlar birçok hakikat üretilmesine neden olur. Sanat da bu üretimin bir parçasıdır -ki bu durumda hakikat, çoğuldur. Bilim-din-devlet yapılarının, tüm sosyal kurumların kendilerine özgü kuralları vardır ve bunlar hakikat oyununun taraflarıdır. Yalancı, 'hakikati bilen' oluşuyla bozguncudur, skandal yaratandır ve yalancı olduğunu gizleyendir. Herkesin hakikatten korktuğunu 
iddia eden Nietzsche'ye göre (2000: 98-110), insan hakikatle yüzleşmekten kaçındığı için yalana sığınır -ki, gerçek yaşamın mümkün olduğu tek yer tiyatrodur. Çünkü hakikat tiyatroda görünür hale gelir.

\section{Yalandan Tiyatro ya da Tiyatro'da Yalan}

Tiyatro sanatı mimesisin doğası gereği bir kurgulama ya da kurmaca eylemidir -ki bu eylemin özü, seyirciyi bir 'yalan'a inandırmaya dayanır. Gerçeğin '-mış gibi' yapılarak taklit edilmesiyle başlayan sahneleme, seyircinin bir kurmaca içinde kandırılması değil, aksine bilinçli bir şekilde ‘yalan’a ortak oluşuyla paylaşılan bir estetiktir. Kırsal dağınıklıktan kentsel düzene geçilerek oluşturulan toplumsal yapı, adına 'hayat' denilen ve günlük ilişkilerle üretilen bir kurmacaya dönüşür. Yalan, sanatla herhangi bir münasebete geçmeden önce bu kurmaca içinde varlık bulur. Yalanın imtiyazlı alanı olan kurmaca gerek yaşamsal gerekse sanatsal olsun, insanlığın tek ortak ürünüdür (Randall, 1999: 27-42). Hayatın kurmacasını sanatın kurmacasına dönüştüren ve bunu hakikati ortaya koyarak yapan tüm eserler, görmenin dilini kullanır. Tiyatro da, görmenin dilini oyun diline dönüştüren bir sanat olarak tıpkı hakikat gibi çoğul anlam taşıyan bir sanattır. Tek başına yapılmadığı gibi, tek bir kişiyi de hedeflemez yani, seyircisiz olamaz. Bu durumda Giovanni Sartori'nin (2006: 11) 'homo videns/görenizleyen insan' dediği seyirci de, bilinçli olarak kurmacanın kandırmacasına dâhil olduğu için 'yalanın ortağı' haline gelir. Hakikatin katılı̆̆ karşısında bir yalana ortak olmaya neden gereksinim duyulduğu da ancak tiyatro estetiğiyle açıklanabilir.

Gerçeğin kendisini mimesis olarak değerlendiren Platon, dünyada olan her şeyin evrensel hakikatin taklidi olduğunu, tiyatronun hakikate ancak üçüncü dereceden yaklaşan bir kopya olduğunu iddia etse de tiyatronun özü, insana ve hakikate ilişkin işleviyle açığa çıkar. Hakikat, insanın coğrafyası, ırkı, dili, dini gözetilmeksizin, doğa karşısında verdiği mücadelenin organik bir yapı kazanmış ürünüdür. Bu ilişki başlangıçta doğaya karşı savaşma, birlik olma aracılığıyla kurulur. Doğayla savaşım halinde olma, toplumsal kuralların da belirleyicisidir. Örneğin mevsimlerin değişimi reddedilmez; aksine uyum sağlanır. Kent yaşamına geçilmesiyle toplumları yönlendirmeye başlayan kapitalizm, hakikatin ya da yalanın o topluma göre şekillenmesine yol açar. Hakikate ulaşmak için verilen her mücadelede yeni bir gerçek ortaya çıkar ve dünya daha da karmaşıklaşır. Bu karmaşa içinde insan, diğerleriyle ortak bir duygu dünyasında yaşama gereksinimi duyar ki bu gereksinim ilkel ya da uygar ayrımına gidilmeksizin zamansız-uzamsız bir beklentidir (Caudwell, 1988: 161-165). Tiyatronun amacı da bu ortak duygu dünyasını yaratabilmektir. Seyirci bu ortaklığın hazzına varmak için tiyatroya gelir. Bir yalana ortak olmanın/bile isteye seyretmenin/katılmanın altında yatan hakikatin karşısında ya da onunla yüzleşmede yalnız olmadığını bilmektir. Çünkü arkaik devirlerden bu yana insana doğa karşısında güç veren tek eylem, topluca katılımdır.

Toplumsal olmaya koşullandırılmış bir dünyaya ait olan insanın doğasında açıkça dile getirilmeyen duygular, tiyatronun konusu olur. Var olan düzene karşı gelme, iktidara başkaldırma, kendini felakete sürükleyeceğini bildiği halde doğru bildiğinden şaşmamadaki özgürleştirici tutkudur o duygular. Antik Yunan tragedyalarında trajik kahramanı hamartiaya götüren hybristir. Duyguların hakikat içindeki öneminin, gücünün farkında olan tiyatro, bu fark edişiyle özgürleşir, çünkü insanın duygularını değiştirme gücüne sahiptir ve böylece toplumsala koşullandırılmış insanın bireysel farklılıklarının kavranmasına ve eyleme geçilmesine 'eylem'le aracılık eder -ki oyun, hali hazırda bir eylemdir. Eylemin özünde insanın algılayış biçimini güzelleştirmek, olması gerekeni hatırlatmak, olanın aksayan yanlarını göstererek insanların değişmesine öncülük etmek yatar (Caudwell, 1988: 170-184). Öte yandan ne hakikat ne de 'güzel' tek başına eyleme götüren kılavuzlar değildir. Dolayısıyla bir kandırmaca olamazlar. Hakikati referans alan tiyatronun kandırmacası, seyirciyi eyleme ikna etme ya da başka türlü olmaya yönelik bir baskıdır. 
Tiyatro, kendisi için gerekli olan kaynağı, günlük yaşamdan alır. Başkalarını belli bir biçimde hareket etmeye ve hissetmeye yönlendirmek, tiyatro estetiğinin itici gücüdür. Seyirci olanın, olması gereken biçime dönüşebilmesi için gerekenleri kabul ettikçe tiyatronun kandırmacası dışsal ve içsel bir gerçekliğe ulaşır. Hakikat, somut yaşayışta açığa çıktığına göre, tiyatro bu yaşantıdan doğar ve yine ona döndüğü için -yalanı araç edinenhakikat olur. Çünkü oyun yazarı, oyuncu ve seyirci bu yaşantının bir uzantısıdır. Başta oyun yazarları, sonra yönetmen, tasarımcı ve oyuncular 'meslekten yalancı' olsalar da, yalanın peşine düşmedeki asıl amaçları hakikate ulaşmaktır. Heidegger'in (2008: 12-29) dasein açıklamasında olduğu gibi varlık, nasıl kendisini dert eden biri olmadığı sürece anlaşılamıyorsa, hakikat de, hakikati dert eden biri olmadığı sürece görünür hale gelemez ve hakikatin görünür olabilmesi 'yalan'a dayalıdır. Oyun yazarı, böylesi bir dert edinmeyle, hayal-gerçek arasındaki sınırıaşabilmek için kurmacayı kullanır. Yalanın tüm çetrefil hallerini, ironiyle beslenerek çoğalışını, gizlenişini, kendini ortaya çıkarışını en açık gösteren yazarlardır. 0 halde oyun yazarı, ilk yalancıdır. Kılık değiştirmiş bir mitten söz eder ve bu aslında hakikatin simgelerle bir bütüne kavuşturulması ve yeniden dile getirilmesidir. Olanı göstermeye çalışan tiyatro, seyircinin gerçeklik algısı içinde hakikatle yalanın ayrıştırılmasına aracılık eder. Hakikat açı ve aleni olan, yalan ise kıvrımlı olandır - -̇yon dilinde hakikat sözcüğü 'açıktan', yalan ise 'kıvrımlı' anlamına gelmektedir. Diğer bir deyişle: "kurmaca hakikatin 'muhteşem sürprizine' erişmek için dolambaçlı bir yoldan, yalanın kıvrımlarından geçer" (Forrester, 1999: 46).

Oyun yazarı oyununu, mimesis aracılığıyla kendi mitini yaratarak kurgular. Mit yaratma, sanatçının grup psikolojisinden kurtulma hamlesi olarak kabul edilebilir. Freud'a göre bu hamle, yazarın hakikate giden yolu keşfetmesinin kanıtıdır. Yazar, yarattığı kahramanlarla kendisini hakikate eriştirirken seyirciyi de hakikate giden hayal katına yükseltir (Forrester, 1999: 47-52). Yazar, yarattığı oyun kişilerinin ardına gizlenen yalancı olarak, durmadan yer değiştiren, ortaya konulan gerçekliğin yarattığı çatışmada her iki tarafı da anlayıp çözümleyen gizli öznedir ve homo videns yazarın 'gör' dediğini görür. Dolayısıyla tiyatronun kurmacası, yalanlarla hakikatin sistematik bir biçimde karıştırılmasıdır -zira tiyatro hakikaten yalandır. Seyirciye istediği mesajı ulaştırmak, oyun dilini yaratabilmek ve yalanını sergileyebilmek için 'dil'i, kasten bir araç olarak kullanır.

Tiyatroda dil aracılığıyla görünür hale gelen hakikat, Heidegger'e göre sanat eserinde kendini esere koyarak var eder. Var-olanın hakikati sanat eserinde kavranır. 0 halde tiyatro, yalandan öte, kendini var-olanın hakikatine koyandır ve gerçek de hakikatte var olandır. Heidegger ‘yalan' sözcüğünü kullanmasa da, hakikatin varlığının hakikat olmayanda duyumsanabileceğini savunur. Seyirci hakikat olmayan aracılığıyla hakikate ulaşmanın hazzını yaşar. Oyunun gerçekliği, hakikatin oyunda işbaşında olmasıyla ve gerçekleşmesiyle belirlenir. Tiyatroda dünya ile yeryüzünün -insan ile doğanın- karşı karşıyalığı bir çatışmadır. Yeryüzü gizleyen, dünya açığa çıkaran olarak daima çatışma halindedir ve bu çatışmada tarafların kendilerine ait varlıkları yok olmaz, her biri kendi kendisinin iddiasındadır. Tiyatro dünya kurarak, yeryüzü üreterek bu çatışmayı sürdürür ve hakikat bu çatışmanın sürdürülmesiyle gerçekleşir. Tiyatro, gerçeğin basitçe doğadan taklit edilmesi olmadığı gibi yeniden üretilmesi anlamına da gelmez. Çünkü tiyatronun evrenselliği, ancak, hakikatin zamansız oluşuyla açıklanabilir ve çıkış noktası ‘yalan' değil, hakikattir (Heidegger, 2007: 29-69).

Homo Videns'in tiyatroya neden gereksinim duyduğu ya da aldığı hazzın kaynağının ne olduğunu sorgulayanlardan biri de Pascal'dır (2009: 34-41). Tiyatroyu, yalanı gerçeğe yaklaşmak için kullanan sanat olarak gören düşünür, insanın yanı başında duran hakikati izlemesinin alınan hazzın asal kaynağı olduğunu savunur ve bu yüzden tiyatro vazgeçilmezdir. Pascal'a göre bu vazgeçmezliğin altında yatan durum, dönüp bakmadığımız, görmeyi reddettiğimiz hakikate dair ne varsa -nesne, olgu, durum- tiyatro tüm bunları sahnede görünür hale getirdiği için hayranlık yaratır. 
Tiyatro seyircisinin karanlığıniçinde sahne aydınlığına ortak olan mimik ve jestleri gibi tüm tepkileri oyunun araçlarıdır. Böylece tiyatro, seyircinin varlığıyla birlikte, sıradan bir yaşamın ritmini bozarak sıra dışı bir etkinliğe ulaşır. Çünkü oyun, "özgürce razı olunan, ama tamamen emredici kurallara uygun olarak belirli zaman ve mekân sınırları içinde gerçekleştirilen, bizatihi bir amaca sahip olan, bir gerilim ve sevinç duygusu ile 'alışılmış hayat'tan 'başka türlü olmak' bilincinin eşlik ettiği, iradi bir eylem ya da faaliyettir" (Huizinga, 1995: 48). Oyun, insanın içinde bulunduğu durumu/gerçeği/hakikati irdelemek adına yazarın-oyuncunun-tasarımcının-yönetmenin deneyimlediklerini somutlaştırır. Bu somutlaştırmanın amacl, bireysel ya da toplumsal bir düzeltme, sağaltma yaratabilmektir ve tiyatro, insanın evrensel bir özne olarak içeride yaşadıklarını, bir nesne olarak dışarıdan görülebilir hale getirme çabasının ürünüdür (Farago, 2006: 18-22).

Tiyatronun indirgenemez kolektifliği insanlık durumunun toplumsal yapısının da işlevsel örneğidir. Çoğulcu bir sanat oluşu, insanın bir başkasıyla ilişkiye girmesi üzerine kurulu olan toplum düzenine benzeyen tek sanattır. Anlatılan/gösterilen ne olursa olsun, birden fazla insanın bir araya gelmesine koşulludur. Dolayısıyla bu benzerlik, varlığın 'dramatik karakteri' olarak adlandırılabilir. Dramatik olan, diyalektik bir çıkış yolu arayan insanın hakikat karşısında ya da içinde bulunduğu durumda oluşan diyalektik çatışmanın özüyle açığa çıkar. Seyirci, tiyatroda kendi hikayesine benzer hikayeleri izlerken değişmeyen diyalektik bir çatışmaya tanık olur -ki bu tanıklık evrensel arketip duygularla harekete geçer. Antik devirlere ait bir oyunda, örneğin Antigone'de iktidarın baskısına başkaldıran bireyin yaşadıkları, günümüz seyircisinin de çıkış yolu aradığı değişmez sorunsallardandır. Seyirci kendi durumuyla yüzleştiğinde konumunu keşfeder. Phedre'nin imkânsız aşkına duyduğu keder, yaşanılmamış, söylenmemiş duyguların sağaltımına aracı olur. "Burada izleyicinin, arketipik durum üzerindeki yansıması söz konusudur; bizim durumumuzun, içimizde yaşayan, bizleri kışkırtan ve bazen bize acı çektiren duyguların evrenselliğinin keşfedilmesiyle yaşanan duygusal bir boşalma söz konusudur. Bu yüzden, her tiyatro karakterinin kısmen bütün toplumu cisimleştirdiğini söyleyebiliriz" (Farago, 2006: 24). Tiyatroda yaratılan kurmaca, sadece duygulara değil, düşünsel boyutu oluşuyla benliğin gelişmesine de etki eder. Böylece oyunun konusu, insanlığın kendi eserinin bir ürünü haline gelir. Baudelaire'e göre, sahnede olan ne varsa sahte olduğu için gerçeğe daha yakındır; çünkü yalan söylemeyi bir kenara bırakmayı bilirler (Farago, 2006: 25-27).

\section{Sonuç}

Tiyatro, hakikate ulaşmak adına, görünenin içinde başka -yalandan- bir dünya yaratır ama bunu gerçeğe benzerlik ilkesiyle yapar. Yalanın ötesinde duran hakikati keşfetmek için 'yorumlama' gerek-şarttır. Kurmacadaki kandırmaca, aldatmadan ziyade bir yorumun temsili ve o yoruma seyirciyi ikna etme çabasıdır. Oyun bittiğinde, ışıklar açılır ve seyirci rutin yaşam ritmine geri döner. Kurmacanın kandırmacası sona ermiştir fakat seyirci artık oyundan önceki seyirci değildir. Homo videns'i öyle ya da böyle, eksik ya da fazla, 'hakikat adına' etkileyen sanatırır tiyatro. Hakikatin doğrudan görülmesinin aracıdır ve hakikati bizden gizleyen ne varsa hepsini devre dışı bırakır. Yalan söylemenin hor görülmeyip kabul edildiği hatta fazla gerçekçi oluşuyla uygulayıcılarının başına çorap ördürdüğü sanattır tiyatro. Nietzsche’ye (2000) göre, hakikatin kendisi yalandan daha tehlikelidir; çünkü varlığın asıl hakikati ‘hiçlik'tir ve onun umutları tüketen boşluğundan ve anlamsızlığından kurtulmanın tek yolu, etkili bir yalandır. Varlığın boşluğunu dolduran en etkili eylemlerden biri olan tiyatro, bireye düzenleyici amaçlar sunar ve bunu oyun'la yapar. Oyun, insanı hiçlikten uzaklaştırır - ki, seyircinin tiyatro salonuna gitmesini sağlayan itki de burada gizlidir. Diğer bir deyişle tiyatro, hakikati gösterme iddiasında olan, yalandan bir etkinlik üreten hayali gerçeklik olarak hiçliğin katı duruşuna rağmen ‘şimdi ve burada' ilkesiyle duyumsanır.

"Hayat dediğimiz yalnızca lazım olan bir kurmacadır. Fantezinin muazzam katkısı olmasaydı gerçeklik sona ererdi." (Eagleton, 2013: 22) 


\section{Kaynakça}

Bataille, Georges (2004). Edebiyat ve Kötülük, çev: Ayşegül Sönmezay, İstanbul: Ayrıntı Yayınları.

Bayladı, Derman (2007). Tanrıların Öyküsü, İstanbul: Say Yayınları.

Caudwell, Christopher (1988). Yanılsama ve Gerçeklik, çev: Mehmet H.Doğan, İstanbul: Payel Yayınları.

Eagleton, Terry (2013). Hayatın Anlamı, çev: Kutlu Tunca, İstanbul: Ayrıntı Yayınları.

Ekman, Paul (2013). Yalan Söylediğimi Nasıl Anladın?!, çev: Erdem İlgi Akter, İstanbul: Okuyanus Yayınları.

Farago, France (2006). Sanat, çev: Özcan Doğan, Ankara: DoğuBatı Yayınları.

Forrester, John (1999). Hakikat Oyunları, çev: Abdullah Yılmaz, İstanbul: Ayrıntı Yayınları.

Foucault, Michel (2005). Doğruyu Söylemek, çev: Kerem Eksen, İstanbul; Ayrıntı Yayınları.

Heidegger, Martin (2007). Sanat Eserinin Kökeni, çev: Fatih Tepebaşlı, Ankara: De Ki Yayınları.

(2008). Varlık ve Zaman, çev: Kaan H.Ökten, İstanbul: Agora Kitaplığı Yayınları.

Huizinga, Johan (1995). Homo Ludens, çev: M.Ali Kılıçbay, İstanbul; Ayrıntı Yayınları.

Mayer, Claudia (2008). Yalana Övgü, çev: Nihal Ünver, Ankara: Phoenix Yayınları.

Moliere (1965). Amphitryon, çev: Ali Teoman, İstanbul: MEB Yayınları.

Nietzsche, Friedrich (2000). Ecce Homo, çev: Can Alkor, İstanbul: Yapı Kredi Yayınları.

Oral, Osman (2004). “Kur'an ve Hadisler Işığında Yalan ve Zararları”, Yeni Ümit Dergisi (66), 121-138, İstanbul: Işık Yayınları.

Pascal, Blaise (2009). Düşünceler, çev: İ.Zeki Eyüboğlu, İstanbul: Say Yayınları.

Plautus (1974). Amphitryon, çev: Nurullah Ataç, İstanbul: Hürriyet Yayınları.

Randall, William L. (1999). Bizi Biz Yapan Hikayeler, çev: Şen Süer Kaya, İstanbul: Ayrıntı Yayınları.
Sartori, Giovanni (2006). Görmenin iktidarı, çev: Gül Batuş, Bahar Ulukan, İstanbul: KaraKutu Yayınları.

Seager, Dr. Paul - Mann, Dr. Sandi (2010). Yalan, çev: M. Onur Doğan, İstanbul: Sel Yayınları.

Türk Dil Kurumu (1998). Türkçe Sözlük, Ankara: Türk Dil Kurumu Yayınları.

Tepe, Harun (2003). Platon'dan Habermas'a Felsefede Doğruluk ya da Hakikat, Ankara: Imge Kitabevi.

Turgut, İhsan (1991). Sanat Felsefesi, İzmir: Bilgehan Matbaası.

Williams, Bernard (2006). Hakikat ve Hakikatlilik, çev: Ertürk Demirel, İstanbul: Ayrıntı Yayınları. 